\title{
Social and medical determinants of quality of life and life satisfaction in women with Turner syndrome
}

\author{
Wacław Jeż', A-D, F, Beata Tobiasz-Adamczyk 2, A, C, F, Piotr Brzyski2, C, F, Mikołaj Majkowicz 3, A, F, \\ Piotr Pankiewicz ${ }^{4}, \mathrm{D}, \mathrm{F}$, Tomasz J. Irzyniec ${ }^{5,6, A-D, F}$ \\ 1 Outpatient Clinic for Women with Turner Syndrome, Specialist Hospital No. 2, Bytom, Poland \\ ${ }^{2}$ Chair of Epidemiology and Preventive Medicine, Jagiellonian University Medical College, Kraków, Poland \\ ${ }^{3}$ Department of Quality of Life Research, Medical University of Gdańsk, Poland \\ ${ }^{4}$ Department of Adult Psychiatry, Medical University of Gdańsk, Poland \\ ${ }^{5}$ Department of Health Promotion and Community Nursing, Faculty of Health Sciences, Medical University of Silesia, Katowice, Poland \\ ${ }^{6}$ Department of Nephrology/ENDO, Hospital of Ministry of the Interior and Administration, Katowice, Poland \\ A - research concept and design; B - collection and/or assembly of data; $\mathrm{C}$ - data analysis and interpretation; \\ $D$ - writing the article; $E$ - critical revision of the article; $F$ - final approval of the article
}

Address for correspondence

Tomasz Irzyniec

E-mail: tirzyniec@sum.edu.pl

Funding sources

None declared

\section{Conflict of interest}

None declared

Received on July 18, 2016

Reviewed on September 14, 2016

Accepted on November 14, 2016

DOI

\section{Abstract}

Background. Turner syndrome (TS) appears in women as a result of the lack of part or the whole of one of the $X$ chromosomes. It is characterized by the occurrence of low height, hypogonadism, numerous developmental defects, and is often accompanied by psychological disturbances.

Objectives. Although the phenotype characteristics of women with TS are quite well documented, the knowledge of the impact of Turner syndrome on the satisfaction with life is still insufficient. The aim of our study was to assess the impact of TS on selected variables of quality of life, and hence also life satisfaction in women with this syndrome.

Material and methods. The research was carried out in a group of 176 women with TS starting March 1995. The patients underwent anthropological and medical examinations, and their medical histories were taken using a questionnaire that included demographic and psychosocial items as well as issues related to selected variables of quality of life. In our research model, general life satisfaction was a dependent variable. The statistical analysis was conducted using the eta and Cramer's V correlation coefficients as well as a multidimensional logistic regression model.

Results. The main determinants of dissatisfaction with life in women with TS were short stature and feelings of loneliness and being handicapped.

Conclusions. The determinants of life satisfaction in women with Turner syndrome were closely related to the private life of the study participants, in particular self-perception and feelings concerning their health status.

Key words: education, life satisfaction, health-related quality of life, Turner syndrome, sexual sphere

\section{$10.17219 /$ acem/66986}

\section{Copyright}




\section{Introduction}

Turner syndrome (TS) is named for Dr. Henry Turner, who described the disorder in 1938. TS occurs in women and is characterized by abnormalities in the quantity or structure of sex chromosomes. The syndrome is most frequently characterized by gonadal dysgenesis and somatic disorders, the most important of which is short stature. ${ }^{1,2}$ Hormonal studies typically reveal low circulating concentrations of ovarian steroids and high concentrations of gonadotropins in women aged 14 and above. In very few women with TS, the ovaries show cyclic hormonal activity manifested by the menstrual cycle and even fertility. ${ }^{3}$ TS affects one in every 2,500 women. Hence, it can be speculated there are approx. 8000 women with Turner syndrome in Poland, of whom 5000 are above 18 years of age. ${ }^{4}$ Although the characteristics of the TS phenotype have been well documented, the knowledge on the impact of the disorder on quality of life, including body image, feelings, social functioning and interaction, and general life satisfaction, remains limited. Social stigmatization makes women with TS feel different compared to healthy women. The disease significantly hinders their psychosocial functioning, in particular at those life stages when the sense of attractiveness associated with appearance is developing; women with Turner syndrome are concerned about short stature and femininity disorders.

Entering the world of independent social relations partly depends on how women with Turner syndrome accept their life situation. However, during the period of primary socialization, it also depends on their readiness to perform different social roles equal to those of healthy women, and not to condemn themselves for social isolation. The studies concerning different aspects of psychosocial functioning of women with TS have not yielded clear results. Some studies indicated there were certain difficulties and limitations in the social functioning of women with TS, while other reports confirmed the chance of normal functioning despite the limitations caused by Turner syndrome. ${ }^{5-8}$

Quality of life assessment has been a subject of theoretical considerations and empirical studies. At present, most researchers agree regarding the multidimensionality and subjective nature of quality of life (QoL) assessments. Some degree of simplification allows the identification of 2 QoL levels: 1) quality of life as a general subjective assessment of an individual's life progress; life satisfaction is one of the measures of quality of life; 2) QoL is limited to a subjective assessment of the disease that an individual suffers from, and the impact of treatment.

Turner syndrome affects development and is characterized by a variety of medical implications; it also has an impact on several aspects of patients' lives. In our research model, general life satisfaction was a dependent variable. Deeper insight into health-related quality of life based on subjective assessments of women with TS might increase the clinicians' awareness regarding these women's needs, and thus allow better tailoring of the treatment process.

\section{Objectives}

The aim of this study was to assess the impact of Turner syndrome and its biological and psychosocial effects on quality of life, determined on the basis of life satisfaction. We employed the following strategies to accomplish this goal: 1) we described variables that influence quality of life; 2) we searched for life satisfaction parameters which could help assess general quality of life.

\section{Material and methods}

The research was carried out on a group of 176 Polish women with TS who responded to recruitment materials published in newspapers and broadcast in radio and television advertisements. Patients were invited to participate in the examinations starting March 1995. All participants gave their informed written consent to participate in the study. The study procedures were approved by the Bioethics Committee of the Medical University of Silesia. The women's medical histories were taken using a standardized questionnaire, and all medical records were checked by the same group of investigators.

The aim of the questionnaire was not only to collect demographic data but also to gather information on quality of life including social functioning, feelings and sexual activity of women with Turner syndrome. Sex drive and sexual initiation (i.e., having sexual experience) were analyzed as factors linked to the sexual sphere. The effects of TS on psychosocial functioning were analyzed based on the attitudes and behaviors of patients with TS, but also attitudes and behaviors toward these women. The respondents were asked about the causes of TS and how they felt about their short statures. They were also requested to present their assessments regarding the impact of TS on their educational level, occupational status, social life, and attractiveness to men. The women were asked whether their parents' knowledge of the occurrence of Turner syndrome in the family had affected the parents' attitudes toward them. We also asked if Turner syndrome had caused the women's parents to view them differently from their siblings. The participants were then requested to assess the attitudes of other people toward them, and whether they had experienced positive or negative consequences of these attitudes. The psychosocial aspects of life satisfaction were also investigated, including having friends, a sense of loneliness, of being perceived as a worthy human being, self-esteem, assessment of own intellectual abilities, capacity to perform work, self-assessment of own health condition, and feeling handicapped in different areas of life.

The study participants underwent anthropological measurements and medical examinations to identify stature characteristics, body build abnormalities such as webbed necks, turned-in elbows, and genu varum (bow legs), foot and hand anomalies, abnormal appearance of fingers, thin/hypoplastic toenails and thin/hypoplastic/hyperconvex fingernails, 
excessive hair growth, low hairline, pigmented nevi, auricular septal defects, sagging eyelids (ptosis), epicanthal folds, rich eye frames, strabismus, daltonism, and infertility.

Age, educational level, marital status, and habitation were among the variables that were taken into account during the analyses. Age and stature were measured on an interval scale, whereas the other variables were measured on a nominal scale. They were then transformed to binary variables, which reflected the occurrence or nonoccurrence of a given attribute or attitude.

In order to determine QoL, the women with TS were asked questions concerning life satisfaction. The strength of the relationship between the interval variables and life satisfaction was estimated using the eta correlation coefficient; the strength of the relationship between the nominal variables and life satisfaction was estimated using the Cramer's V correlation coefficient. The hypotheses that the correlation coefficient and the obtained logistic regression coefficients differed from 0 were rejected at the significance level of $\mathrm{p}=0.05$.

Quality of life variables were analyzed using a multidimensional logistic regression model. The statistical analysis was performed using SPSS 12 PL for Windows.

\section{Results}

\section{Variables that influenced quality of life and the characteristics of life satisfaction measurement}

\section{Social and demographic characteristics}

The examined women were at the age of $18-53$ years, mean age $25 \pm 7.6$ years. Regarding the skewness of age distribution, other measures of central tendency were considered: the median age was 22 years; the $1^{\text {st }}$ quartile age was 19 years, and the $3^{\text {rd }}$ quartile age was 29 years. The demographic characteristics of our study participants are shown in Table 1.

It should be emphasized though that over $50 \%$ of women had secondary or university education. The majority of the respondents were single, but approx. a quarter of them were married or had a partner. Most women lived with their parents; $17 \%$ lived with a husband or a partner. The majority were inhabitants of urban areas (81.3\%).

The data in Table 2 shows that approx. 1/3 of the study participants negatively assessed the attitudes of other people; $2 / 3$ confirmed they had actually experienced negative attitudes. Approximately $15 \%$ of women believed that Turner syndrome affected their family's attitude toward them, while about $8 \%$ thought that their family position was different from that of their siblings. Almost all had a sense of being perceived as a worthy human being.

The mean height of the examined women was $144.7 \pm 7.2 \mathrm{~cm}$; the median height was $144 \mathrm{~cm}$, and the $1^{\text {st }}$
Table 1. Social and demographic characteristics of study participants

\begin{tabular}{|c|c|c|c|}
\hline \multicolumn{2}{|c|}{ Social and demographic variables } & $\mathrm{n}$ & $\%$ \\
\hline \multirow{4}{*}{ Education } & elementary & 38 & 21.8 \\
\hline & basic technical/trade & 45 & 25.9 \\
\hline & secondary & 80 & 45.9 \\
\hline & university & 11 & 6.4 \\
\hline \multirow{4}{*}{ Marital status } & single & 126 & 71.6 \\
\hline & married & 32 & 18.2 \\
\hline & has a partner & 9 & 5.1 \\
\hline & had a partner & 9 & 5.1 \\
\hline \multirow{4}{*}{ Habitation } & with parents only & 131 & 74.4 \\
\hline & with a partner & 30 & 17 \\
\hline & alone & 8 & 4.5 \\
\hline & other & 7 & 4 \\
\hline \multirow{2}{*}{ Area } & town & 143 & 81.3 \\
\hline & country & 33 & 18.7 \\
\hline
\end{tabular}

Table 2. Assessment of other people's attitudes

\begin{tabular}{|l|c|r|r|}
\hline \multicolumn{1}{|c|}{ Variable } & Answers & $n$ & $\%$ \\
\hline $\begin{array}{l}\text { Negative assessment of other } \\
\text { people's attitudes }\end{array}$ & no & 122 & 69.3 \\
\hline $\begin{array}{l}\text { Experienced negative attitudes } \\
\text { of other people }\end{array}$ & no & 54 & 30.7 \\
\hline $\begin{array}{l}\text { Impact of Turner syndrome } \\
\text { on parents' attitude }\end{array}$ & yes & 117 & 39.5 \\
\hline $\begin{array}{l}\text { Incorrect attitude of their } \\
\text { parents }\end{array}$ & nes & 148 & 84.4 \\
\hline $\begin{array}{l}\text { Different position in the family } \\
\text { compared to brothers and sisters }\end{array}$ & no & 135 & 15.6 \\
\hline Sense of being perceived & selectively & 17 & 76.7 \\
\hline as a worthy human being & yes & 157 & 93.3 \\
\hline Loneliness & no & 124 & 70.9 \\
\hline
\end{tabular}

and $3^{\text {rd }}$ quartiles were $140 \mathrm{~cm}$ and $149 \mathrm{~cm}$, respectively. Dissatisfaction with short stature was expressed by approx. $60 \%$ of women; approx. $40 \%$ believed that their height was the reason for their low physical attractiveness to men. Only approx. $11 \%$ of the examined women thought there was a relationship between their short stature and educational level, and 1/4 believed that their short stature had affected their professional activity. Genu varum (bow legs) was found in $24 \%$ of women. Only $16.5 \%$ admitted having no sex drive (Table 3).

\section{Feeling of being handicapped}

The authors developed a scale to measure the feeling of being handicapped in various spheres of life. Variables related to this feeling exhibited strong correlations. The following binary variables were used as components 
Table 3. Health and body image assessment

\begin{tabular}{|c|c|c|c|}
\hline Variable & Answers & $\mathrm{n}$ & $\%$ \\
\hline \multirow{2}{*}{ Unhappiness about short stature } & no & 70 & 40.9 \\
\hline & yes & 101 & 59.1 \\
\hline \multirow{2}{*}{$\begin{array}{l}\text { Negative impact of short stature } \\
\text { on attractiveness to men }\end{array}$} & no & 104 & 60.8 \\
\hline & yes & 67 & 39.2 \\
\hline \multirow{2}{*}{$\begin{array}{l}\text { Negative impact of short stature } \\
\text { on education }\end{array}$} & no & 156 & 88.6 \\
\hline & yes & 19 & 11.4 \\
\hline \multirow{2}{*}{$\begin{array}{l}\text { Negative impact of short stature } \\
\text { on occupational status }\end{array}$} & no & 141 & 76.1 \\
\hline & yes & 34 & 23.9 \\
\hline \multirow{2}{*}{ Genu varum (bow egs) } & no & 133 & 75.6 \\
\hline & yes & 43 & 24.4 \\
\hline \multirow{2}{*}{ No sex drive } & no & 147 & 83.5 \\
\hline & yes & 29 & 16.5 \\
\hline
\end{tabular}

of the scale (the answers in parentheses are those for which the respondents were given a point):

- Do you feel handicapped? (yes)

- Do you perceive your capacity to perform work as limited? (yes)

- Do you believe your health is impaired? (yes)

- Do you perceive your intellectual abilities as impaired? (yes)

- How do you compare with other people (self-esteem)? (worse)

The scale was characterized by Cronbach's alpha of 0.77 (Table 4).

The distribution of results regarding the degree of feeling handicapped was as follows: score 0 (no feeling of being handicapped) - 100 women $(57.5 \%)$; score $1-18$ (10.3\%); score 2-25 (14.4\%); score 3-17 (9.8\%); score 4-9 (5.2\%); score 5 (the strongest feeling of being handicapped) -5 (2.9\%). Almost $67.8 \%$ of the examined women did not feel handicapped, and only $8.1 \%$ admitted having a feeling of being heavily handicapped.

\section{Satisfaction with life}

Life satisfaction of the study participants was assessed with the question: "Are you satisfied with your life?". The responses were: "yes" (subgroup 1); "no" or "do not know" (subgroup 2). Response distribution was as follows: 129 "yes" (73.3\%); 19 "no" (10.8\%); and 28 "do not know" (15.9\%) options. In further analysis, the "no" and "do not know" responses were combined into 1 category. The majority of women with Turner syndrome (73.3\%) confirmed that they were satisfied with life.

\section{Determinants of general life satisfaction with respect to demographic, medical and psychosocial factors}

Determinants of life satisfaction were sought among the demographic variables, each woman's subjective feelings and opinions about herself, the women's subjective assessments of the views and attitudes of other people, and their actual life situation.

Among the demographic variables, age and social environment at the place of residence were found to be essentially linked to life satisfaction; the magnitude of the

Table 4. Factor analysis (without rotation) and analysis of the internal consistency of feeling handicapped

\begin{tabular}{|c|c|c|c|c|}
\hline \multirow{2}{*}{ Variable } & \multicolumn{2}{|c|}{$\begin{array}{l}\text { Correlation with the principal } \\
\text { component }\end{array}$} & \multirow{2}{*}{$\begin{array}{l}\text { "Question-scale" } \\
\text { correlation }\end{array}$} & \multirow{2}{*}{$\begin{array}{l}\text { Alpha after disregarding } \\
\text { the question }\end{array}$} \\
\hline & 1 & 2 & & \\
\hline Feeling handicapped & 0.9 & -0.3 & 0.78 & 0.62 \\
\hline Work capacity assessed as "rather limited" & 0.74 & 0.37 & 0.55 & 0.72 \\
\hline Health assessed as "rather impaired" & 0.72 & -0.6 & 0.54 & 0.72 \\
\hline Intellectual abilities assessed as "rather impaired" & 0.7 & 0.2 & 0.5 & 0.74 \\
\hline $\begin{array}{l}\text { Self-esteem compared to patient's perception of other } \\
\text { people "worse or unstable" }\end{array}$ & 0.52 & 0.55 & 0.35 & 0.79 \\
\hline
\end{tabular}

Table 5. Demographic variables and life satisfaction in women with Turner syndrome

\begin{tabular}{|c|c|c|c|c|c|c|c|}
\hline & & & Life & & & & \\
\hline & ble & & & no/ & low & Cramer's V & $p$-value \\
\hline & & $\mathrm{n}$ & $\%$ & $n$ & $\%$ & & \\
\hline & with parents only & 100 & 76.3 & 31 & 23.7 & & \\
\hline Hahitation & with partner & 22 & 73.3 & 8 & 26.7 & & \\
\hline 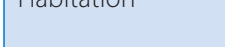 & alone & 2 & 25 & 6 & 75 & 0.24 & $<0.05$ \\
\hline & other & 5 & 71.4 & 2 & 28.6 & & \\
\hline & town & 100 & 69.9 & 43 & 30.1 & & \\
\hline Ared or mestatence & country & 29 & 87.9 & 4 & 12.1 & 0.10 & $<0.03$ \\
\hline
\end{tabular}


correlations was approximately the same. Women who lived alone and in a city reported life dissatisfaction more frequently (Table 5).

The study participants' self-assessment regarding stature, attractiveness and worthiness were most strongly associated with life satisfaction. Life dissatisfaction was more frequently reported by women who were unhappy about their short stature and those who negatively evaluated the impact of short stature on attractiveness to men. A nearly equally strong relationship was found between a sense of being perceived as a worthy human being and life satisfaction. The feeling of loneliness had the strongest impact on life satisfaction, while the negative assessment of the impact of short stature on educational and professional status had a weaker influence on life satisfaction (Table 6).

The relationship between body height and life satisfaction was the strongest, with an eta of 0.48. That is, taller women were more satisfied with life.

Other variables that had a substantial impact on quality of life of women with TS were genu varum (bow legs) and actual experience of negative attitudes of other people.
However, these correlations were slightly weaker than those for the demographic variables.

Considering the attitudes of other people, the recognition that parents' attitudes were incorrect and that the disease affected families' and friends' attitudes toward them had the strongest impact on life satisfaction of women with TS. The feelings that their family position was different from that of their siblings, and that other people had negative attitudes toward them were less strongly correlated with life satisfaction. The degree of feeling handicapped was also a significant predictor of life satisfaction, with an eta of 0.43 (Table 7).

Although this study was correlational rather than experimental, an attempt was made to assess the potential influence of some factors on general quality of life; the assessment was based on life satisfaction. In the logistic regression model, life satisfaction was the main dependent variable, while the other variables were predictors.

The results of multidimensional analysis (the logistic regression model) showed that unhappiness about short stature, loneliness and feeling handicapped were independent

Table 6. Self-assessment of own limitations vs satisfaction with life in women with Turner syndrome

\begin{tabular}{|c|c|c|c|c|c|c|c|}
\hline \multirow{3}{*}{ Variable } & \multirow{3}{*}{ Answers } & \multicolumn{4}{|c|}{ Satisfaction with life } & \multirow{3}{*}{ Cramer's V } & \multirow{3}{*}{$\mathrm{p}$-value } \\
\hline & & \multicolumn{2}{|c|}{ yes } & \multicolumn{2}{|c|}{ no/do not know } & & \\
\hline & & $\mathrm{n}$ & $\%$ & $\mathrm{n}$ & $\%$ & & \\
\hline \multirow{2}{*}{ Dissatisfaction with short stature } & no & 62 & 88.6 & 8 & 11.4 & \multirow{2}{*}{0.29} & \multirow{2}{*}{$<0.001$} \\
\hline & yes & 63 & 62.4 & 38 & 37.6 & & \\
\hline \multirow{2}{*}{$\begin{array}{l}\text { Negative impact of short stature } \\
\text { on education }\end{array}$} & no & 115 & 76.2 & 36 & 23.8 & \multirow{2}{*}{0.17} & \multirow{2}{*}{$<0.05$} \\
\hline & yes & 10 & 52.6 & 9 & 47.4 & & \\
\hline \multirow{2}{*}{$\begin{array}{l}\text { Negative impact of short stature } \\
\text { on professional situation }\end{array}$} & no & 106 & 77.9 & 30 & 22.1 & \multirow{2}{*}{0.23} & \multirow{2}{*}{$<0.005$} \\
\hline & yes & 18 & 52.9 & 16 & 47.1 & & \\
\hline \multirow{2}{*}{$\begin{array}{l}\text { Negative impact of short stature } \\
\text { on attractiveness to men }\end{array}$} & no & 86 & 82.7 & 18 & 17.3 & \multirow{2}{*}{0.27} & \multirow{2}{*}{$<0.001$} \\
\hline & yes & 39 & 58.2 & 28 & 41.8 & & \\
\hline \multirow{2}{*}{$\begin{array}{l}\text { Sense of being perceived } \\
\text { as a worthy human being }\end{array}$} & yes & 121 & 77.1 & 36 & 22.9 & \multirow{2}{*}{0.28} & \multirow{2}{*}{$<0.001$} \\
\hline & selectively & 6 & 35.3 & 11 & 64.7 & & \\
\hline \multirow{2}{*}{ Loneliness } & no & 105 & 84.7 & 19 & 15.3 & \multirow{2}{*}{0.41} & \multirow{2}{*}{$<0.001$} \\
\hline & yes & 23 & 45.1 & 28 & 54.9 & & \\
\hline
\end{tabular}

Table 7. Assessment of other people's attitudes as a determinant of life satisfaction in women with Turner syndrome

\begin{tabular}{|c|c|c|c|c|c|c|c|}
\hline \multirow{3}{*}{ Variable } & \multirow{3}{*}{ Answers } & \multicolumn{4}{|c|}{ Satisfaction with life } & \multirow{3}{*}{ Cramer's V } & \multirow{3}{*}{ p-value } \\
\hline & & \multicolumn{2}{|c|}{ yes } & \multicolumn{2}{|c|}{ no/do not know } & & \\
\hline & & $\mathrm{n}$ & $\%$ & $\mathrm{n}$ & $\%$ & & \\
\hline \multirow{2}{*}{ Incorrect attitude of parents } & no & 109 & 80.7 & 26 & 19.3 & \multirow{2}{*}{0.31} & \multirow{2}{*}{$<0.001$} \\
\hline & yes & 20 & 48.8 & 21 & 51.2 & & \\
\hline \multirow{2}{*}{ Impact of TS on parents' attitude } & no & 117 & 79.1 & 31 & 20.9 & \multirow{2}{*}{0.31} & \multirow{2}{*}{$<0.001$} \\
\hline & yes & 11 & 40.7 & 16 & 59.3 & & \\
\hline \multirow{2}{*}{$\begin{array}{l}\text { Different position in the family } \\
\text { compared to siblings }\end{array}$} & no & 119 & 77.3 & 35 & 22.7 & \multirow{2}{*}{0.26} & \multirow{2}{*}{$<0.001$} \\
\hline & yes & 5 & 35.7 & 9 & 64.3 & & \\
\hline \multirow{2}{*}{$\begin{array}{l}\text { Negative assessment of other } \\
\text { people's attitudes }\end{array}$} & no & 98 & 80.3 & 24 & 19.7 & \multirow{2}{*}{0.24} & \multirow{2}{*}{$<0.005$} \\
\hline & yes & 31 & 57.4 & 23 & 42.6 & & \\
\hline
\end{tabular}


Table 8. Logistic regression: determinants of life satisfaction: "no"/"do not know" vs "yes"

\begin{tabular}{|c|c|c|c|c|c|}
\hline & Variables & OR & & & $\mathrm{p}$-value \\
\hline Age over 32 & & 0.96 & 0.23 & 3.98 & ns \\
\hline & elementary & 1 & - & - & - \\
\hline Education & basic technical/trade & 3.93 & 0.84 & 18.3 & ns \\
\hline & secondary and university & 2.31 & 0.59 & 9.13 & ns \\
\hline & with parents only & 1 & - & - & - \\
\hline & with partner & 1.8 & 0.4 & 8.06 & ns \\
\hline & alone & 8.01 & 0.77 & 83.32 & ns \\
\hline & other & 3.16 & 0.25 & 40.6 & ns \\
\hline Height & & 0.98 & 0.90 & 1.06 & ns \\
\hline No sex drive & & 2.69 & 0.73 & 9.91 & ns \\
\hline Dissatisfacti & stature & 4.11 & 1.28 & 13.19 & $<0.05$ \\
\hline Negative im & stature on attractiveness to men & 2.02 & 0.67 & 6.07 & ns \\
\hline Incorrect att & & 2.85 & 0.91 & 8.94 & ns \\
\hline Sense of bei & as a worthy human being & 3.07 & 0.60 & 15.76 & $<0.05$ \\
\hline Loneliness & & 3.28 & 1.20 & 8.94 & $<0.05$ \\
\hline Degree of fe & pped & 1.53 & 1.08 & 2.16 & ns \\
\hline
\end{tabular}

95\% Cl - 95\% confidence interval; OR - odds ratio; ns - statistically non-significant.

predictors of life satisfaction, and substantially increased the risk of life dissatisfaction in women with Turner syndrome (Table 8).

Although variables such as living alone, education higher than elementary, and incorrect parents' attitudes were not statistically significant $(\mathrm{p}=0.05)$, they also clearly affected satisfaction with life as determined by multidimensional logistic regression.

\section{Discussion}

The study was performed on a relatively large group of women with TS and we believe the results obtained considerably expand the knowledge on quality of life in women with TS. The drawback of the study design was the method of patient recruitment (by response to adverts), which introduced some significant bias. It should be expected that patients with lower quality of life were less ready to answer such adverts. Our study group consisted of well-educated women whose life situation, including the limitations resulting from TS, could be better, although other studies indicate the opposite. Women who participated in the examinations did so voluntarily, indicating higher awareness and better adaptation to life. The psychosocial dimensions of quality of life in women with Turner syndrome are quite diverse; nevertheless, our findings are quite consistent with other studies carried out in this group of women.

The previous studies focused primarily on the results of hormonal treatment, particularly growth hormone $(\mathrm{GH})$, administered to improve quality of life. Carel et al. studied quality of life in young women (aged 22.6 \pm 2.6 years) with TS who had already undergone growth hormone treatment for 5 years, and concluded that quality of life was normal and unaffected by height in young adults with Turner syndrome treated with GH. ${ }^{9}$ The beneficial effects of growth hormone therapy on the patient's quality of life were also reported by Bannink et al. ${ }^{10}$ Ross et al. observed a positive effect of estrogen on the psychological well-being of girls with TS, and emphasized the need to initiate estrogen replacement therapy by the age of 12-14 years in this population. ${ }^{11}$

There are also papers that document the positive influence of GH administered in childhood on quality of life and psychological well-being, although not as explicitly as that of Ross et al. ${ }^{11}$

Amundson et al. compared quality of life in TS women treated with $\mathrm{GH}$ and/or oxandrolone to promote growth with quality of life in a healthy population; they concluded that social isolation was more commonly reported in the whole TS cohort than in the general population. Except for less pain, no significant impact on quality of life attributable to $\mathrm{GH}$ treatment could be found, despite the mean $+5.1 \mathrm{~cm}$ final height. ${ }^{12}$ Taback and Van Vliet used the Short Form (36) Health Survey (SF-36) and found no benefit to or adverse effect on health-related quality of life (HRQoL), either from receiving or not receiving $\mathrm{GH}$ injections. Young adult women with TS had normal HRQoL, suggesting that they adjusted well to life challenges. ${ }^{13}$

Women with TS have reduced levels of androgens due to ovarian failure; androgen insufficiency plays a role in TSimpaired body composition, neurocognition and quality of life. Oral methyl testosterone given for 1 year improved attention, reaction time and verbal memory, and had no effect on executive functions or spatial cognition. Patients reported improved quality of life, including general health, 
coping with stress and sexual desire. ${ }^{14}$ These results indicate that the lower quality of life in women with TS can be improved with pharmacological treatment.

After analyzing the changes in quality of life after childhood GH treatment, Zenaty concluded that, although the women's quality of life appeared to be similar to that of the healthy population, the presence of cardiovascular and otological diseases, and delayed feminization did impair quality of life. Hence, early diagnosis and regular screening from childhood to adulthood are essential to reduce morbidity and improve self-esteem. ${ }^{15}$ Turtle et al. share this opinion. ${ }^{16}$ In the research by Azurah et al. and Robbins et al., it was hypogonadism and amenorrhea that affected life satisfaction, especially regarding sexual function. ${ }^{17,18}$ A great number of factors are related to a patient's QoL. Special and individual protocols should also be assessed in patients with TS. ${ }^{19}$

The results of our research indicate that life satisfaction can be affected by both health-related and demographic variables. Our study revealed lower quality of life in those women with Turner syndrome who were troubled by their short statures, loneliness, feeling of being handicapped, and negative attitudes of other people.

Educational and professional background are essential for QoL, including women with TS. Verlinde et al. assessed the health status, education, occupation, and life situation of 102 women, of whom $40 \%$ reported health problems (most frequently hypertension) and 25\% had undergone spontaneous pubertal development. ${ }^{5}$ Compared to the general population, more women with TS had higher education; $45 \%$ were employed, $70 \%$ lived with their parents, and $17 \%$ were married or lived with partners.

Konradsen and Nielsen examined 69 women with TS as well as their sisters, and found that the disease had no impact on educational level or profession. ${ }^{20}$ It is essential to emphasize that psychosocial functioning in women with TS changes over time and that psychosociological resources are more complex and involved in younger women with TS. ${ }^{21}$ As mentioned in the introduction, our study group consisted of well-educated women, whose life situation could be better if they did not suffer from TS.

The sexual sphere is one of the most important areas of a woman's life, ${ }^{6}$ but Job et al. found that $64 \%$ of their study participants with TS did not show interest in the opposite sex. ${ }^{22}$ Hettmer et al. found that all women identified as feminine and heterosexual. ${ }^{23}$ Women who were put on hormone replacement therapy too late showed lack of mental and social well-being as well as disturbances in sexual function. In our previous paper, we found that the percentage of sexually active women with TS was much smaller than that in the general population, and that these women initiated sex later. Eighty percent of women with TS reported being sexually attracted to men, but only $29 \%$ initiated sexual activity. Women with TS differ from healthy women in the general Polish population in that they show less interest in men, less frequent sexual activity, later initiation of sexual activity, and they have orgasms less frequently. The most frequent reason for diminished sexual activity is a lack of a regular partner. We concluded that the quality of sexual life of women with TS differs from that of women in the general population. ${ }^{6}$ Women with TS also differ from healthy women in lifestyle. ${ }^{24}$

Sexual activity as a component of QoL was also considered in a variety of aspects, including medical (hypogonadism, amenorrhea) and pharmacological ones (GH, oxandrolone, methyltestosterone). ${ }^{17,18,25}$ Only in the latter study did the patients report improved QoL. Other authors found no differences in QoL between sexually active and inactive women with TS. Nevertheless, the sexually active patients did have poorer arousal outcomes compared to the general population. No differences between sexually active and inactive women with TS were found in their SF-36 scores or clinical and anthropomorphic characteristics. ${ }^{18}$ Data collected from women with TS and their families indicated that the women, their families, health care workers, and society did not have sufficient information about Turner syndrome and did not know how to help patients with TS. ${ }^{26}$

To sum up, research results confirm that Turner syndrome has a substantial impact on women's satisfaction with life. TS-related stigmatization (short stature and feelings of being handicapped and lonely) significantly determines the women's general assessments of their quality of life.

\section{Conclusions}

Life satisfaction was the lowest in those women with Turner syndrome who were unhappy about their short stature. Loneliness diminished satisfaction with life in women with Turner syndrome. The feeling of being handicapped in different areas decreased life satisfaction in women with Turner syndrome. The determinants of life satisfaction in women with Turner syndrome were closely related to the private life of the study participants, and their feelings concerning health status.

\section{References}

1. Turner H. A syndrome of infantilism congenital webbed neck, and cubitus valgus. Endocrinology. 1938;23:566-574.

2. Davenport ML. Approach to the patient with Turner syndrome. J Clin Endocrinol Metab. 2010;95:1487-1495.

3. Jeż W, Makieła E, Lewandowski P. Pregnancy in a woman with Turner Syndrome: Two new cases. Gin Pol. 2006;77:307-309.

4. Wiśniewski A. Chorzy na zespół Turnera są wśród Twoich pacjentów. Klinika. 1993;2:40-43.

5. Verlinde F, Massa G, Lagrou K, et al. Health and psychosocial status of patients with Turner's syndrome after transition to adulthood: The Belgian experience. Horm Res. 2004;62:161-167.

6. Lew-Starowicz Z, Jeż W, Irzyniec T, Kabzińska M, Boćkowska E. Sexual aspects of women with Turner's syndrome. Sex Disabil. 2003;21: 241-248.

7. Boman UW, Bryman I, Möller A. Psychological well-being in women with Turner syndrome: Somatic and social correlates. J Psychosom Obstet Gynaecol. 2004;25:211-219. 
8. Dołęga Z, Turek A, Irzyniec T, Jeż W. Gender, body image and sense of loneliness of women after receiving a Turner's syndrome diagnosis. Psychol J. 2012;18:143-153.

9. Carel JC, Ecosse E, Bastie-Sigeac I, et al. Quality of life determinants in young women with Turner's syndrome after growth hormone treatment: Results of the StaTur population-based cohort study. J Clin Endocrinol Metab. 2005;90:1992-1997.

10. Bannink EM, Raat H, Mulder PG, de Muinck Keizer-Schrama SM. Quality of life after growth hormone therapy and induced puberty in women with Turner syndrome. J Pediatr. 2006;148:95-101.

11. Ross JL, McCauley E, Roeltgen D, et al. Self-concept and behavior in adolescent girls with Turner syndrome: Potential estrogen effects. J Clin Endocrinol Metab. 1996;81:926-931.

12. Amundson E, Boman UW, Barrenäs ML, Bryman I, Landin-Wilhelmsen K. Impact of growth hormone therapy on quality of life in adults with Turner syndrome. J Clin Endocrinol Metab. 2010;95:1355-1359.

13. Taback SP, Van Vliet G. Health-related quality of life of young adults with Turner syndrome following a long-term randomized controlled trial of recombinant human growth hormone. BMC Pediatrics. 2011; 11:49. doi:10.1186/1471-2431-11-49

14. Zuckerman-Levin N, Frolova-Bishara T, Militianu D, Levin M, AharonPeretz J, Hochberg Z. Androgen replacement therapy in Turner syndrome: A pilot study. J Clin Endocrinol Metab. 2009;94:4820-4827.

15. Zenaty D, Laurent M, Carel JC, Leger J. Turner Syndrome: What's new in medical care? Arch Pediatr. 2011;18:1343-1347.

16. Turtle EJ, Sule AA, Bath LE. Assessing and addressing cardiovascular risk in adults with Turner syndrome. Clin Endocrinol (Oxf). 2013;78: 639-645.

17. Azurah AG, Zainuddin AA, Jayasinghe Y. Diagnostic pitfalls in the evaluation and management of amenorrhea in adolescents. J Reprod Med. 2013;58;324-336.
18. Robbins CC, Wolfe M, Squires K, Jungheim E, Weiner L. Discussion: 'Congenital hypogonadisms impair quality of life and sexual function,' by Ross et al. Am J Obstet Gynecol. 2013;208:e1-e3.

19. Nelke KH, Pawlak W, Gerber H, Leszczyszyn J. Head and neck cancer patients' quality of life. Adv Clin Exp Med. 2014;23:1019-1027.

20. Konradsen B, Nielsen J. Follow up study of 69 Turner women. In: Hibi I, Takano K, eds. Basic and Clinical Approach to Turner's Syndrome. Amsterdam: Elsevier; 1993:177-183.

21. Dołęga Z, Jeż W, Irzyniec T. The cohort effect in studies related to differences in psychosocial functioning of women with Turner syndrome. Endokrynol Pol. 2014;65:287-294.

22. Job JC, Laudier F; The Cabi Collaborative Study Group. Three-year results of treatment with growth hormone, alone or associated with oxandrolone in girls with Turner's syndrome. Horm Res. 1991;35:229.

23. Hettmer E, Hoepffner W, Keller E, Brähler E. Studies on sexual development, sexual behavior and ability to experience sex of young women with Ullrich-Turner syndrome. Ther Umsch. 1995;52:146-149.

24. Jeż W, Irzyniec T, Lew-Starowicz Z. Sexual life and lifestyle of women with Turner's syndrome. Sex Disabil. 2006;24:207-212.

25. Menke LA, Sas TC, Visser M, et al. The effect of the weak androgen oxandrolone on psychological and behavioral characteristics in growth hormone-treated girls with Turner syndrome. Horm Behav. 2010;57:297-305.

26. Jeż W. Non-medical care of the patient with Turner's syndrome and the use by parents and husband help in solving their own problems associated with Turner syndrome. In: Jeż W, Cybulska D, Buliński A, Jarząb B, Jarząb J, eds. Turner's Syndrome. Poznan: Termedia Wydawnictwa Medyczne; 2010:136-141. 